\title{
Impact of value co-creation on firm performance: Mediating role of strategic advantages
}

\author{
Brice Berinyuy Fonjong ${ }^{1 *}$ Hongyun Tian $^{2}$ \\ 1. School of Management, Department of Management, Jiangsu University, 301 Xuefu Road, Jingkou \\ District, Zhenjiang, Jiangsu, P.R. China. \\ 2. School of Management, Department of Management, Jiangsu University, 301 Xuefu Road, Jingkou \\ District, Zhenjiang, Jiangsu, P.R. China. \\ *Email of the corresponding author: fonjongbrice@gmail.com
}

\begin{abstract}
Value co-creation (VC), the unified motive of different stakeholders of a firm to improve the VC process, is a crucial in mounting mutual goals. Though, the current movement of a growing size and number of enormous customers has placed the smaller industrial dealers in subservient roles and consigned their goalmouth to persistence. Hypotheses were analyzed by structured equation modeling using partial least squares 3.0. Data were collected by field survey from March May 2019. Convenient random sampling used to select the respondents. Study, examine the influences of VC on small and medium producer (SMP) performance in Cameroon. They provide components or parts to huge companies' buyers, notified that the $\mathrm{VC}$ does have a positive and statistically significant direct and indirect influence on the organizational performance (OP) through their improved strategic competitive advantages (CA). Consequently, $\mathrm{VC}$ is not only significant for only big firms, but also to small and medium producers (SMP), as it promotes them from a commercial correlation to a cooperative link with their partners.
\end{abstract}

Keywords: Value Co-creation (VC), Competitive Advantage (CA), Small and medium producer (SMP), Organizational performance (OP)

DOI: $10.7176 / \mathrm{EJBM} / 11-21-20$

Publication date:July $31^{\text {st }} 2019$

\section{Introduction}

In today's dramatic environment, firms struggle to improve the efficiency successfulness of their entire network/value chains for enriched organization doings/activities. For SMPs that supply components to large companies, sustaining good connections or linkages with clients is crucial to effectively and efficiently contest with other providers in the same sector/industry. The necessity for lasting mutual commercial relationships with partner firms is mounting shared goals (Kramer and Porter, 2011). Conversely, as the rivalry has become increase, and the inclination of customers being colossal business leaders, several SMP suppliers, find themselves in subservient roles and their major goal of making profits, lessen to subsistence by offering high quality goods at lesser prices (S. M. Lee and Lim, 2007). Most of the multinational organizations and large companies are continually pushed to provide innovative features, in their products/services by adopting and focusing on innovation. With the continuous emphasis on open-innovation, they are looking for SMPs that are reliable, malleable and agile partners for VC (Roy and Sivakumar, 2010).

An innovation inclination has fetched a dare to firms is VC. VC includes cooperation among varied stakeholders in the network comprising customers, purchaser and suppliers, to generate mutual value (S. M. Lee and Trimi, 2018; Ramaswamy and Ozcan, 2014). VC is considered vital as the life cycle of goods/services is becoming gradually diminutive and novelty has become the enduring policy for organizations of all numbers and sizes across industries/sector, products and borders. Large organizations often execute "disruptive innovation (DI), innovating against their own business models and products, even when everything seems to go fine" (Christensen, Raynor, and McDonald, 2015). They are continuously eyeing for new services, goods and ideas from not big, agile 
organizations, few of them may be entirely dissimilar to them (S. Lee and Olson, 2010). A decade ago, offering good quality product/services at a low price was no more a competitive advantage for the companies either smaller or larger. Yet, SMPs must advance competitive advantage by adopting the hand of open innovation, agility, and the tacit ability for VC (S. M. Lee, Olson, and Trimi, 2012). Therefore, in order to cope with a fluctuating environment, it's mandatory for all of the firms to must share the related information, VC, and goal of innovation.

Prior research on VC is in early stage, concentrating largely on theoretical ideas (Payne, Storbacka, and Frow, 2008) and case studies (Ramaswamy and Gouillart, 2010). Specifically, there is a scarcity of pragmatic scholarships on VC and its affiliation with OP. Broad level of preceding educations on the supplier-shopper correlation were conducted based form purchaser view point, particularly on supplier selection approaches (Ordoobadi and Wang, 2011), VC (Chatain, 2011), Information sharing (Liu, Li, Shi, and Liu, 2017), technical links (Fossas-Olalla, Minguela-Rata, López-Sánchez, and Fernández-Menéndez, 2015), and issues particularly related to trust (Balboni, Marchi, and Vignola, 2017). Because SMP providers are finding it progressively more perplexing to contest and endure, in this scholarship, we explore the supplier-buyer correlations from the supplier's viewpoint. In specific, we investigate how SMP suppliers can use VC for common goals with large organizations/buyers as an approach to advance their enterprise performance. Data was collected from 240 SMPs, which provides components to multinational companies operating in Africa, whose sustainability and achievement be contingent wholly on productivity of cooperative associations with their clients. The study subsidizes to the present VC works as well as implications.

\section{Background}

\subsection{Value Co-creation (VC)}

The fluctuations in market necessitates efficiency and speed, not only in daily operations, but entire industries/sectors. To triumph this goal, functioning links between organizations internal as well as external stakeholders in the value chain netwrok should be built on collaboration, flexibility, and faith, instead of perpendicular profit-making diminuendos (Teece, 2014). Cooperative associations can happen when the endproduct users, supplier, and buyers stake the goal of the $\mathrm{VC}$ and their dealings exceed afar the straight obliging ones (Williamson and De Meyer, 2012).

$\mathrm{VC}$ is not a unique idea. Governments, enterprises, humans and countries have derived numerous equally beneficial results through it for several years. In the 1950s, an unexpected power down killed a newborn infant, baby, an incident happened in a hospital affiliated with the "University of Minnesota in the U.S". While the doctor was visualizing a manner to impede such a tragedy from trendy again, they see a "medical device repairman working near the hospital, who said, you do not have to worry about a power outage if you combine the micro battery I have developed with the cardiac pacemaker".

Research on VC is in beginning stage. Utmost preceding educations on the topic were largely theoretical one, dealing with the rudimentary idea and significance of VC. Payne et al., (2008) elaborate an enterprise cocreative activity as an interactive plug among clients and the firms'. They beliefs the idea that a "pre-condition for developing the co-creative firm-customer relationship is understanding consumers' desired experience". In this study, we define VC "as a type of collaboration where diverse interested parties develop a value creation ecosystem, to create and achieve shared values for the purpose of benefiting the customer demand" and afar for the better good (S. M. Lee and Lim, 2018).

Freshly, there have been numerous empirical investigations and case studies that dedicated typically on customer-centered VC. Grissemann and Stokburger-Sauer, (2012) showed the importance of VC impacts on the gratification of customers. Koo \& Rha, (2012) inspected means to encourage VC between enterprises and customers and extracted preventive drivers from the viewpoints of the organization and customer. Palma, Trimi, and Hong, (2018) rummage-sale a review to search the external and internal influences that impact clients' contribution in VC. Hong and Lee, (2015) smeared a VC method for emerging common goals in a practical assignment of a "culture-village redevelopment in Korea". The consequences of the research validated actuating the village inhabitants to contribute in co-creation was a critical driver. McColl-Kennedy, Hogan, Witell, and 
Snyder, (2017) examined the effects of VC among "medical staff and healthcare customers on the wellbeing of patients, and found a positive impact".

\subsection{Small and medium producers (SMP)}

Around the globe, in developed or developing countries small and medium enterprises (SMEs), account for approximately $70 \%$ of job creation and greater than $60 \%$ contribution to GDP (Clifton, 2016). In most of the emerging economies, SMP encompasses the essential strength of the growth of the economy and its sustainability. In developed countries, such as Germany, USA, UK and Japan, SMPs are analytically crucial as they practice the source vile of the economy. In contrast to emerging countries like Malaysia, UAE to the same extent distinctive it's because of the government policies and intervention into the enterprise operations.

There has been a wide exploration of the supplier-buyer association. Utmost of the scholarships in the works dealt with the customer's viewpoint, specifically the expansion of important assessment criteria for choosing purveyors and approaches for provider selection. Few of the most latest scholarships on the topic sightseen customary standards for example functional and cost competency (Luo, Liu, Yang, Maksimov, and Hou, 2015), risk management ( $\mathrm{Wu}, \mathrm{Li}, \mathrm{Chu}$, and Sculli, 2013), and restructuring and design of goods/services (Lin and Chen, 2015), as well as more modern influences counting sustainability and green management (Jabbour and Jabbour, 2009), pliability (Gunasekaran, Rai, and Griffin, 2011), and innovation cohort (Mooi and Frambach, 2012).

Big global producers have a benefit/competitive edge over their smaller providers, because of the leading role in sector, availability of resources, professional management, frugalities of scale, and worldwide innovativeness of search ability (von Hippel, 2017). They are dominant when it approaches to the connections with their SMP dealers as there are numerous provider choices availability (Wang and Jap, 2017). Therefore, SMPs often fight to form and retain a good link to their big organizations through partnership (Fossas-Olalla et al., 2015). To spurt from the indefensible subservient position in the association with buyers, SMPs have numerous strategic options. At-first, SMPs can struggle to produce highly qualitative products that are outstanding in all perspective of tasks that the purchasers necessitate. At that time, these SMPs would become "order winners or outsourcing partners" based on their functional capability. At-second approach SMPs can take is to bring into line with their own innovative ability with that of the customers. The entrenched innovation approach would permit these SMPs to become vital companions in a "win-win innovation" correlation (Y. Kim, Choi, and Skilton, 2015). At-third, few worldwide SMPs are liberated innovation bests in their specialization areas. Such enterprises entice the consideration of big organizations for joint undertakings or licensing engagements (Monczka, Petersen, Handfield, and Ragatz, 1998).

To protect viable request for their goods, SMPs must constantly follow innovation to provide innovative products to their customers, so that thoughts for upcoming business models or new technical innovations. Such novelty competence would deliver SMPs the muscle to contribute in VC mutual goals as like partners despite of subservient supply chain providers (Lee and Trimi, 2018).

\section{Conceptual framework and hypotheses development}

\subsection{Conceptual framework}

The prime motive of this work is to examine how VC with enormous enterprise purchasers' influences the performance of SMP dealers through are obtaining SA "vis-à-vis" other contenders. Grounded on the pertinent works, the elements that we used in this investigation for $\mathrm{VC}$ comprises mutual advantages, risk uncertainty, information sharing, and shared values. The common faith is that VC would positively and significantly influence SMPs overall performance. The performance, enlargement would be a consequence of SMPs progressing from their subservient role, simply being dealers of quality goods at rational prices to huge buyers, to the role of lively cooperating companions. Becoming participating coworkers and contributors in VC with their partners (buyers) permits SMPs to advance CA. Such benefit would comprise flexibility, fairness, visibility, and association commitment (Zhang, Vonderembse, and Lim, 2003). Furthermore, the OP would be enhanced not only because of 
the $\mathrm{CA}$ improvement as a consequence of $\mathrm{VC}$, but also as a result of the straightforward and crucial effects of the augmented non-financial OP. Our recommended study model is reflected in Fig. 1.

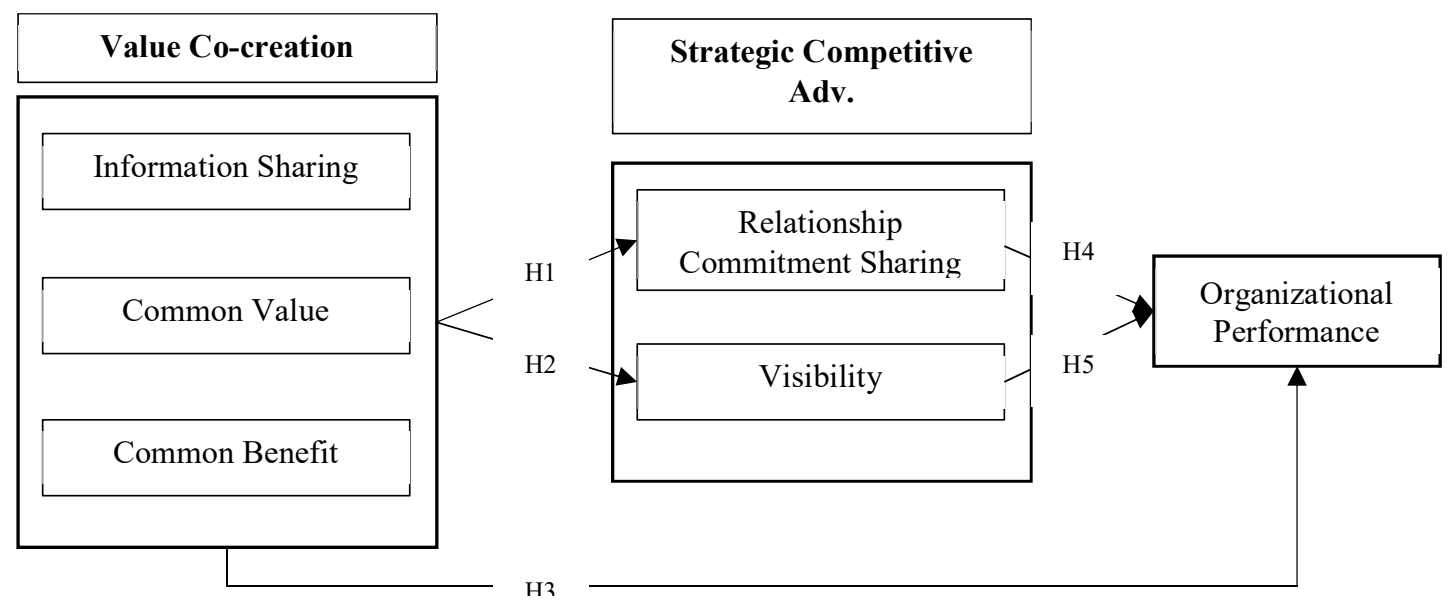

Figure 1. Conceptual framework

\subsection{Research hypotheses}

\subsubsection{Value co-creation and relationship commitment sharing (RC)}

There are several definitions, of RC, in this study, we defined it as "the relative intensity of a person's sense of unity or involvement in the workplace" (Mowday, Porter, and Steers, 2013). Though it's vital to define the association among firms and individuals, the sense of promise has been protracted as a "condition to build successful business relationships among organizations" (Dwyer, Schurr, and Oh, 1987). RC amongst enterprises leads to collaboration and encourages an optimistic correlation by sharing value (Morgan and Hunt, 1994). RC amid to a supplier and a buyer comes from the sharing of common goals (Wu et al., 2013). Hence, being dedicated, for enterprises that have sensitive affection to each other and that are eyeing to withstand commonly beneficial associations, means that it is essential to admit a few of the short term sacrifices (Anderson and Weitz, 1992). In this paper, based on the works, we define RC as " a willingness to make efforts for achieving long-term mutual benefits in business, and not aiming at short-term gains by frequently changing partners." Therefore, for small firms, to persuade their larger partners/suppliers pledge to long-term associations with them, despite of frequently and easily being released as associates, must deliver SA that makes them unique. Hence, we suggest the resulting hypothesis as:

H1. Value co-creation has a positive and statistically significant influence on relationship commitment sharing.

\subsubsection{Value Co-creation and visibility (V)}

Now a day's in an environment of profit-making and winning the hearts of customers, competition is not any longer among and between individual organizations, but among and between enterprise value chains/networks. For a network to do work effectively, the most significant influences are visibility and limpidity among affiliate organizations. Visibility differs from capability to interchange transaction info in actual between the contributing participants (Mukhopadhyay and Kekre, 2002), to distribute info connected to the supply and demand (Swaminathan and Tayur, 2003), and share know-how, ability and competence (Mooi and Frambach, 2012). In this paper, we define it as "ability to predict long-term demand and therefore respond quickly to environmental changes, in collaboration with partners." Therefore, we propose:

\section{H2. Value co-creation has a positive and statistically significant influence on visibility.}

\subsubsection{Value Co-creation and Organizational Performance (OP)}

Lee and Olson (2010) recommended VC as a key constituent in the mega-innovation plan, which appeals novelty of innovation approaches. Nam et al., (2009) classified clients' co-creation doings into 
evaluation/improvement, operation/maintenance, delivery/production and design/strategy. The study claimed that the exchange amid goods/services and co-creation occur through a "value network", and this, in turn, has an optimistic influence on the OP. Lim and Hong, (2016) study also revealed that VC has a progressive effect on enterprise performance. In addition, Lim and Hong (2017) scrutiny on the co-creation and role of leadership on the OP. Outcomes of the study, showed the positive effects of leadership and VC on firms' performance. Therefore, we suggest:

H3. Value Co-creation has a positive and statistically significant influence on organizational performance.

\subsubsection{Relationship Commitment sharing and Organizational Performance}

$\mathrm{RC}$ is an important element for the formation of an effective commercial-based business (Anderson and Narus, 1990). Morgan and Hunt (1994) proposed that RC to a spouse advances collaboration and strengthens the relationship, which in turn improves the OP. When the association among the supplier and buyer is for a long lasting, both parties involved in the relationship have a benefit from the pledge/commitment: the buyer corporation buys quality of goods at an affordable cost as a consequence of handling inventories more effectively and efficiently, and providers have a safe market for their goods (Kalwani and Narayandas, 1995; Selnes and Sallis, 2003). Though, in today's fluctuating environment of DI, for big companies, just having means of good quality goods/services at decent prices is not enough. They must have the competence for a quick response to agility and DI (Christensen et al., 2015). Most of the big firms can depend on their SMP stand parts for the ability to originate and adjust rapidly to variation. (Venkatraman and Ramanujam, 1986) proposed functioning performance as a key element of non-monetary performance. Furthermore, they offered technological efficiency, good quality, effectiveness of market, introduction of new product, market share and manufacturing value added, as other elements of non-monetary performance. Hence, we suggest:

\section{H4. Relationship Commitment sharing has a positive and significant influence Organizational Performance.}

\subsubsection{Visibility and Organizational Performance}

In today's world business faces more fluctuation in the market environment than before, hence, precise estimation of the future (Canton, 2015) is vital for a sustainability of OP. Visibility of the firms' in the sooq is needed for any enterprise to entice consumer responsiveness to its goods and also more companion organization for its network value/value chain. V is particularly significant to SMP providers as their OP and sustainability rely greatly on emerging profit-making associations with buyer enterprises. From the purchasers' viewpoint, the V of an SMP provider means its ability to react rapidly to instable market circumstances and varying demands of the customer/buyer. A large level of visibility of provider grounded on their agility promises decline of information inequity among partner organization, and consequently help improve their abilities to react rapidly to changes in demand (Camuffo, Furlan, Romano, and Vinelli, 2007). The successful application of progressive information technology for constructing shared platforms to make and share info that can sustenance the competencies of affiliate organizations to co-create common goals (Porter and Kramer, 2011) which in turn lets quick reaction to vicissitudes in the real-time environment (Martínez Sánchez and Pérez Pérez, 2005). Visibility is a vital SA factor for SMP providers/suppliers which can have an optimistic influence on their OP. Thus, we suggest:

\section{H5. Visibility has a positive and statistically significant influence on organizational performance.}

\subsubsection{Mediating Effect}

Mohsenzadeh and Ahmadian, (2016), a study on 200 Iranian firms, conclude that, competitive advantage mediates the association between manufacturing competences and enterprise performance. In addition, Nuryakin, Aryanto, and Setiawan, (2018), a study based on Indonesian 305 firms involved the mediating role of VC and found the negative association between relationship abilities and performance, while found the positive association among information related to market and enterprise performance. They entail the significant mediating effect of VC. Furthermore, Verma, Rajagopal, and Mercado, (2013), scholarship on 119 Mexican's financial firms showed the positive mediation effects of competitive advantages between service co-creation and firms' performance. Though, D. W. Kim, Trimi, Hong, and Lim, (2019), also found the positive and significant mediating impacts of co-creation and small medium manufacturer supplier performance. Therefore, we proposed following hypothesis: 
H6. Relationship commitment sharing positively and significantly mediates the relationship between value cocreation and organizational performance.

H7. Visibility positively and significantly mediates the relationship between value co-creation and organizational performance.

\section{Research Methodology}

\subsection{Data collection and Questionnaire design}

Data was collected from March 2019 to May 2019 in Cameroon a developing country of Africa. We have employed closed ended questionnaire. A field survey conducted in top five populated cities of the country, the reason behind the selection of only top five cities include the 1- Most of the SMP suppliers resides in those cities. 2- Education level of the respondents in such cities is higher. The questionnaire includes the five sections. First section includes the demographic information of the respondents. Second - Fifth section includes the questions items used to measure the constructs used in the study (e.g. Value creation; relationship commitment; visibility and organizational performance).

\subsection{Sample Selection}

A convenient random sampling techniques used to select the respondents. A sample of $(\mathrm{N}=240)$ respondents represents the population of the country. Respondents based on five major resides in the country (e.g. Douala, Yaoundé, Bamenda, Bafoussam, and Garoua). Those cities selected grounded on the educational level, population, size and number of the firms. A profile of the respondents reflected in table 1 given below. As reflected in table below $74.5 \%$ of respondents are male, and the rest of $25.41 \%$ are female. $35 \%$ of respondents fall in the age of $36-40$ years, followed by $26.25 \%$ falls in the age of $31-35$. In addition, $47.5 \%$ of respondents fall in the middle management level. Looking at education perspective, $36.25 \%$ of the respondents have an undergraduate degree/diploma, while $31.66 \%$ have a master's degree. $43.33 \%$ of them working in an organization having employees' in the range of $101-200.23 .33 \%$ of them works in manufacturing industry, followed $22.08 \%$ in food and hospitality.

\subsection{Measurement Scale}

In this study we have used one independent variable which include three dimensions as mentioned in the figure 1.5 points Likert scale used into the study, in which $1=$ strongly disagree, to $5=$ strongly agree. We have accumulated the items of dimension to measure the value co-creation. Hence, 12 items used to assess the construct. The scale adopted from the well-developed studies scale for the VC taken from the study of (Heide and Stump, 1995; Lambert, Emmelhainz, and Gardner, 1999). In addition, 5 items used to measure the relationship commitment, scale widely used in previous studies of (Moorman, Zaltman, and Deshpande, 1992; Anderson and Weitz 1992; Wu et al. 2003). Visibility, assessed by 5 items scale adopted from (Narver and Slater, 1990; Zaheer, McEvily, and Perrone, 1998). Furthermore, the overall organizational performance measure by 8 items, scale adopted from study of (Venkatraman and Ramanujam 1986).

\subsection{Analytical Techniques}

In this study we have scrutinized the measurement model by Smart Partial lest square software 3.2.8. Specifically techniques of algorithm and bootstrapping has been used to measure the validity and reliability of constructs. The preferences of using this software involve the wide popularity, and acceptability of its application (J. F. Hair, Sarstedt, Ringle, and Mena, 2012; Qalati, Yuan, Iqbal, Hussain, and Ali, 2019). Furthermore involves the comprehensive information about variables (J. F. Hair, Ringle, and Sarstedt, 2011). 
Table 1. Respondents' profile

\begin{tabular}{|c|c|c|c|}
\hline Demographic Constructs & & Size & Percentage \% \\
\hline \multicolumn{4}{|l|}{ Gender } \\
\hline & Male & 179 & 74.58 \\
\hline & Female & 61 & 25.41 \\
\hline \multicolumn{4}{|l|}{ Age } \\
\hline & $>18$ & 37 & 15.41 \\
\hline & $25-30$ & 29 & 12.08 \\
\hline & $31-35$ & 63 & 26.25 \\
\hline & $36-40$ & 84 & 35.00 \\
\hline & $>40$ & 27 & 11.25 \\
\hline \multicolumn{4}{|l|}{ Management Level } \\
\hline & Top Management & 75 & 31.25 \\
\hline & Middle Management & 114 & 47.50 \\
\hline & Lower Management & 51 & 21.25 \\
\hline \multicolumn{4}{|l|}{ Education Leve } \\
\hline & Junior/High School & 44 & 18.33 \\
\hline & Undergraduate & 87 & 36.25 \\
\hline & Master & 76 & 31.66 \\
\hline & $\mathrm{PhD}$ & 33 & 13.75 \\
\hline \multicolumn{4}{|l|}{ Size of the Organization } \\
\hline & $<100$ & 60 & 25.00 \\
\hline & $101-200$ & 104 & 43.33 \\
\hline & $>200$ & 76 & 31.66 \\
\hline \multicolumn{4}{|l|}{ Industry } \\
\hline & Health & 34 & 14.16 \\
\hline & IT & 49 & 20.41 \\
\hline & Manufacturing & 56 & 23.33 \\
\hline & Service & 28 & 11.66 \\
\hline & Food \& Hospitality & 53 & 22.08 \\
\hline & Other & 20 & 8.333 \\
\hline
\end{tabular}

\section{Results}

The table -2 : show the results related to the assessment of the constructs. As per rule of thumb set by (Nunnally 1978), the coefficient value of CA should exceed $\mathbf{0 . 7}$. Reliability will be excellent if it falls in between 0.7 to 0.9 it will be named high reliability. If in between 0.5 to 0.7 it will become moderate. And if it will be $<0.5$ it will categorize low. As reflected in table below all of the constructs $(\mathrm{OP}=0.872 ; \mathrm{RC}=0.870 ; \mathrm{V}=0.763 ;$ and $\mathrm{VC}=$ 0.921 ) fall in the range of 0.7 to 0.9 that's why called excellent reliability. In addition, related to the loading, (Chin, 1998), proposed that loadings should exceed 0.5. Furthermore, Bagozzi and Yi, (1988), stated that the value of AVE should be greater than the 0.5. And According to Gefen, Straub, and Boudreau, (2000), composite reliability of construct should be greater than 0.7 . Hence, keeping in view all the rules of thumbs related to reliability and validity standards, the results of the study founded satisfactory and meet the basic criteria developed by the previous scholars. 
Table 2. Measurement model evolution

\begin{tabular}{|c|c|c|c|c|c|}
\hline Constructs & Loadings & Items & CA & $\mathbf{C R}$ & AVE \\
\hline Organizational & OP1 & 0.82 & 0.872 & 0.904 & 0.611 \\
\hline \multirow[t]{5}{*}{ Performance } & $\mathrm{OP} 2$ & 0.842 & & & \\
\hline & OP3 & 0.787 & & & \\
\hline & OP4 & 0.707 & & & \\
\hline & OP5 & 0.793 & & & \\
\hline & OP8 & 0.731 & & & \\
\hline Relationship & $\mathrm{RC} 1$ & 0.807 & 0.870 & 0.905 & 0.656 \\
\hline \multirow[t]{4}{*}{ Commitment } & $\mathrm{RC} 2$ & 0.868 & & & \\
\hline & $\mathrm{RC} 3$ & 0.822 & & & \\
\hline & $\mathrm{RC} 4$ & 0.815 & & & \\
\hline & $\mathrm{RC} 5$ & 0.733 & & & \\
\hline \multirow[t]{5}{*}{ Visibility } & $\mathrm{V} 1$ & 0.592 & 0.763 & 0.835 & 0.508 \\
\hline & $\mathrm{V} 2$ & 0.704 & & & \\
\hline & $\mathrm{V} 3$ & 0.594 & & & \\
\hline & $\mathrm{V} 4$ & 0.829 & & & \\
\hline & $\mathrm{V} 5$ & 0.808 & & & \\
\hline Value & $\mathrm{VC} 1$ & 0.715 & 0.921 & 0.933 & 0.538 \\
\hline \multirow[t]{11}{*}{ Co-creation } & $\mathrm{VC} 10$ & 0.761 & & & \\
\hline & $\mathrm{VC} 11$ & 0.657 & & & \\
\hline & $\mathrm{VC} 12$ & 0.763 & & & \\
\hline & $\mathrm{VC} 2$ & 0.625 & & & \\
\hline & VC3 & 0.663 & & & \\
\hline & $\mathrm{VC} 4$ & 0.738 & & & \\
\hline & VC5 & 0.794 & & & \\
\hline & VC6 & 0.796 & & & \\
\hline & $\mathrm{VC7}$ & 0.851 & & & \\
\hline & $\mathrm{VC} 8$ & 0.665 & & & \\
\hline & VC9 & 0.744 & & & \\
\hline
\end{tabular}

Two methods were used to evaluate the "discriminant validity" of the variables. 1) It was ensured that the cross loadings of indicators should be greater than any other opposing constructs (Hair, et al. 2012). 2) According to the Fornell and Larcker, (1981) criterion, the square root of AVE for each construct should exceed the intercorrelations of the construct with other model constructs" (Table 3). Hence, both approaches ensured the satisfaction of the results and validity.

Table 3. Discriminant validity coefficients

\begin{tabular}{c|c|c|c|c}
\hline & OP & RC & VC & V \\
\hline Organizational Performance & $\mathbf{0 . 7 8 2 *}$ & & & \\
\hline Relationship Commitment & 0.775 & $\mathbf{0 . 8 1 0 *}$ & & \\
\hline Value Creation & 0.586 & 0.600 & $\mathbf{0 . 7 3 4 *}$ & \\
\hline Visibility & 0.649 & 0.741 & 0.571 & $\mathbf{0 . 7 1 2 *}$ \\
\hline
\end{tabular}

Note: * Bold values represent the square root of average variance extracted (AVE). 
Table 4. Path coefficients and hypothesis testing

\begin{tabular}{|c|c|c|c|c|c|c|c|}
\hline Effects & Hypothesis & Relationship & Beta & S.D & t-value & p-value & Decision \\
\hline \multicolumn{8}{|c|}{ Direct Effect } \\
\hline & $\mathrm{H} 1$ & $\mathrm{VC}->\mathrm{RC}$ & 0.600 & 0.04 & 14.908 & $0.000 * *$ & Supported \\
\hline & $\mathrm{H} 2$ & $\mathrm{VC}->\mathrm{V}$ & 0.571 & 0.046 & 12.453 & $0.000 * *$ & Supported \\
\hline & $\mathrm{H} 3$ & VC $->$ OP & 0.486 & 0.038 & 12.727 & $0.000^{* *}$ & Supported \\
\hline & $\mathrm{H} 4$ & $\mathrm{RC}->\mathrm{OP}$ & 0.652 & 0.053 & 12.361 & $0.000^{* *}$ & Supported \\
\hline & $\mathrm{H} 5$ & $\mathrm{~V}->\mathrm{OP}$ & 0.166 & 0.061 & 2.717 & $0.007^{* *}$ & Supported \\
\hline \multicolumn{8}{|c|}{ Indirect Effect } \\
\hline & H6 & $\begin{array}{c}\mathrm{VC}->\mathrm{RC}-> \\
\mathrm{OP} \\
\end{array}$ & 0.391 & 0.045 & 8.726 & $0.000 * *$ & Supported \\
\hline & $\mathrm{H} 7$ & $\mathrm{VC} \rightarrow \mathrm{V} \rightarrow \mathrm{OP}$ & 0.095 & 0.037 & 2.537 & $0.011 * *$ & Supported \\
\hline
\end{tabular}

Note: $* *$ p-value $<0.05$, t-value $>2$.

The table given below contain the values of coefficient of determination. It shows the percentage change in dependent variable incur by independent. (J. Hair, Black, Babin, and Anderson, 2010), defined it as the proportion defined by independent variables. In other words it tells how much change in dependent variable incur because of independent variable. Table -5 show three models. In first model: $\mathrm{R}^{2}$ of organizational performance, have positive coefficient 0.613 , and adjusted $\mathrm{R}^{2} 0.610$. In other way we can say that $61.3 \%$ changes in OP incur because of the all the independent variables. In second model that change was $36.0 \%$. While in third model $32.6 \%$ changes in visibility occur because of value co-creation. According to (J. F. Hair et al., 2011), there are three value of coefficient of determination $0.75,0.5$ or 0.25 and they called them as substantial, moderate or weak. If coefficient of determination falls within range of $0.75 \mathrm{or}>$ it will become substantial. While if between $0.25-0.75$. It will become moderate. If falls $<0.25$ it will be considered as weak. Hence, the value founded in study, shown in the table underneath falls in moderate range.

Table 5. Analysis of $\mathrm{R}^{2}$

\begin{tabular}{l|l|c|c|c}
\hline & Path & R Square & $\begin{array}{c}\text { R Square } \\
\text { Adjusted }\end{array}$ & Decision \\
\hline Model -1 & OP & 0.613 & 0.610 & Moderate \\
\hline Model -2 & RC & 0.360 & 0.357 & Moderate \\
\hline Model -3 & V & 0.326 & 0.323 & Moderate \\
\hline
\end{tabular}

\section{Discussion and Conclusion}

The aims of this study was to investigate the influence of SMPs' contributions in VC with their big partners on their overall business performance. This scholarship was done grounded on responses of 240 SMPs that source parts/components to big organizations and that contribute in $\mathrm{VC}$ activities. The results displayed that contributing in VC with large firms eventually advances SMP organizational performance, not just probabilities for existence.

As reflected in table 4; H1: supported with (positive beta $=0.60, \mathrm{~S} . \mathrm{D}=0.04$, t-value $=14.908$ and $\mathrm{p}$-value $=0.000$ ). Results founded consistent with the previous studies (Wu et al., 2013). H2: supported with (beta $=0.571$, $\mathrm{S} . \mathrm{D}=0.046$, t-value $=12.453$ and $\mathrm{p}$-value $=0.000)$. Results of the hypothesis consistent with study of (Mukhopadhyay and Kekre, 2002). H3: supported with (beta $=0.486$, S.D $=0.038$, t-value $=12.727$ and p-value $=0.000$ ). Results founded consistent with (Lim and Hong 2017). H4: supported with (positive beta = 0.652, S.D $=0.053, \mathrm{t}$-value $=12.361$ and $\mathrm{p}$-value $=0.000)$. Results were consistent with the study of (Selnes and Sallis, 2003). H5: supported with (beta $=0.166, \mathrm{~S} . \mathrm{D}=0.061$, $\mathrm{t}$-value $=2.717$, and $\mathrm{p}$-value $=0.007$ ). Results of the hypothesis consistent with study of (Sanchez and Perez, 2005). In addition, H5; and H6 were constructed to assess the mediating effects. Hence, the both hypotheses supported with positive beta coefficients, and their $\mathrm{t}$-value $>2$, and 
p-value $<0.05$. Results founded supported and consistent with the previous work of (Kima, et al. 2019). This study, by confirming the association among VC and OP, makes aids to the strategy works and may also inspire further educations in the investigation area of supplier-buyer relationships. The outcome of the scholarship confirmed that for SMP suppliers that delivering goods/ elements to big firms, VC can be a key strategy to advance their commercial association from subordinate stations to equal associates. As a result of this altered commercial association, SMP providers can advance their SA drivers for improved organizational performance.

From the practitioner's viewpoint, the aid of this education is that, by displaying the experiential influence of VC, SMP dealers can emphasis on numerous factors of SA that have critical optimistic influence on firms performance. This outcome is particularly significant as SMP dealers can now emphasis on their VC efforts so as to improve the SA in forming mutually win-win association/link with their buyers.

\section{Limitation and future direction}

This scholarship has numerous limitations. This study dedicated on the supplier's/provider's side and did not reflect the possible benefit that purchasers can get from VC. Thus, it is recommended to conduct an investigation which involve the both side's supplier and buyer. Pertaining towards the constructs apart from the three dimensions focused, there could be others like mutual risk, intensity of relationship. Hence, future studies should focus on others dimensions of VC and CA (e.g. flexibility, fairness). Environmental effects can be used as moderator in the upcoming studies. This work concentrated on the VC performance of SMPs only. It would be curious to enlarge the scope of study to involve varied sectors such as service and logistics. Furthermore, the success of VC may alter over time. Hence, longitudinal research are recommended to internment the influence of VC on OP over time. The commercial link among SMP providers and purchaser alter according to the external environment and culture factors of the host country. Therefore, the effects of VC between buyer and suppliers firms should be investigated across political, economic, and cultural, limits. The confines of this study offers several prospects for upcoming studies.

\section{References}

Anderson, E., \& Weitz, B. (1992). The use of pledges to build and sustain commitment in distribution channels. Journal of marketing research, 29(1), 18-34.

Bagozzi, R. P., \& Yi, Y. (1988). On the evaluation of structural equation models. Journal of the academy of marketing science, 16(1), 74-94.

Balboni, B., Marchi, G., \&Vignola, M. (2017). Knowledge transfer in the context of buyer supplier relationship: An analysis of a supplier's customer portfolio. Journal of Business Research, 80(Nov.), 277-287

Camuffo, A., Furlan, A., Romano, P., \& Vinelli, A. (2007). Routes towards supplier and production network internationalisation. International Journal of Operations \& Production Management, 27(4), 371-387.

Canton, J. (2015). Future smart: Managing the game-changing trends that will transform your world: Da Capo Press.

Chatain, O. (2011). Value creation, competition, and performance in buyer-supplier relationships. Strategic Management Journal, 32(1), 76-102.

Chin, W. W. (1998). The partial least squares approach to structural equation modeling. Modern methods for business research, 295(2), 295-336.

Christensen, C. M., Raynor, M. E., \& McDonald, R. (2015). What is disruptive innovation. Harvard business review, 93(12), 44-53.

Clifton, J. (2016). America's middle class: Crushed. Small Business Journal, 15-17.

Dwyer, F. R., Schurr, P. H., \& Oh, S. (1987). Developing buyer-seller relationships. Journal of marketing, 51(2), 11-27.

Fornell, C., \& Larcker, D. F. (1981). Structural equation models with unobservable variables and measurement error: Algebra and statistics: SAGE Publications Sage CA: Los Angeles, CA.

Fossas-Olalla, M., Minguela-Rata, B., López-Sánchez, J.-I., \& Fernández-Menéndez, J. (2015). Product innovation: When should suppliers begin to collaborate? Journal of Business Research, 68(7), 1404-1406.

Gefen, D., Straub, D., \& Boudreau, M.-C. (2000). Structural equation modeling and regression: Guidelines for research practice. Communications of the association for information systems, 4(1), 7.

Grissemann, U. S., \& Stokburger-Sauer, N. E. (2012). Customer co-creation of travel services: The role of company support and customer satisfaction with the co-creation performance. Tourism management, 33(6), 1483-1492. 
Gunasekaran, A., Rai, B. K., \& Griffin, M. (2011). Resilience and competitiveness of small and medium size enterprises: an empirical research. International Journal of Production Research, 49(18), 5489-5509.

Hair, J., Black, W., Babin, B., \& Anderson, R. (2010). Multivariate data analysis 7th edth ed: Upper Saddle River (NJ): Prentice Hall.

Hair, J. F., Ringle, C. M., \& Sarstedt, M. (2011). PLS-SEM: Indeed a silver bullet. Journal of Marketing theory and Practice, 19(2), 139-152.

Hair, J. F., Sarstedt, M., Ringle, C. M., \& Mena, J. A. (2012). An assessment of the use of partial least squares structural equation modeling in marketing research. Journal of the academy of marketing science, 40(3), 414-433.

Heide, J. B., \& Stump, R. L. (1995). Performance implications of buyer-supplier relationships in industrial markets: a transaction cost explanation. Journal of Business Research, 32(1), 57-66.

Hong, S.-G., \& Lee, H.-M. (2015). Developing Gamcheon Cultural Village as a tourist destination through cocreation. Service Business, 9(4), 749-769.

Jabbour, A. B. L., \& Jabbour, C. J. (2009). Are supplier selection criteria going green? Case studies of companies in Brazil. Industrial Management \& Data Systems, 109(4), 477-495.

Kalwani, M. U., \& Narayandas, N. (1995). Long-term manufacturer-supplier relationships: do they pay off for supplier firms? Journal of marketing, 59(1), 1-16.

Kim, D. W., Trimi, S., Hong, S. G., \& Lim, S. (2019). Effects of co-creation on organizational performance of small and medium manufacturers. Journal of Business Research.

Kim, Y., Choi, T. Y., \& Skilton, P. F. (2015). Buyer-supplier embeddedness and patterns of innovation. International Journal of Operations \& Production Management, 35(3), 318-345.

Koo, H., \& Rha, J. (2012). How can we facilitate co-creation of value? Findings from expert panel interviews. $J$. Consum. Cult, 15, 159-186.

Kramer, M. R., \& Porter, M. (2011). Creating shared value. Harvard business review, 89(1/2), 62-77.

Lambert, D. M., Emmelhainz, M. A., \& Gardner, J. T. (1999). Building successful logistics partnerships. Journal of business logistics, 20(1), 165.

Lee, S., \& Olson, D. (2010). Convergenomics: Ashgate Publishing, London.

Lee, S. M., \& Lim, S.-b. (2007). Factors influencing suppliers' participation in private electronic markets. Service Business, 1(1), 41-62.

Lee, S. M., \& Lim, S. (2018). Living innovation: from value creation to the greater good: Emerald Publishing Limited.

Lee, S. M., Olson, D. L., \& Trimi, S. (2012). Co-innovation: convergenomics, collaboration, and co-creation for organizational values. Management decision, 50(5), 817-831.

Lee, S. M., \& Trimi, S. (2018). Innovation for creating a smart future. Journal of Innovation \& Knowledge, 3(1), $1-8$.

Lim, S. B., \& Hong, S.-G. (2016). Co-creation and Reform of State Owned Enterprise A Case Study about President Hahm's Co-creation Driven Leadership at Kangwon Land Casino and Resort. International Information Institute (Tokyo). Information, 19(11A), 5057.

Lim, S., \& Hong, S. (2017). Co-creation driven innovation strategy of Kangwon land casino and resort. Seoul, Korea: Yuwon Books

Lin, Y.-T., \& Chen, Y.-J. (2015). Competitive outsourcing: choosing between value-added services and key component supplying capability. International Journal of Production Research, 53(12), 3635-3650.

Liu, Y., Li, Y., Shi, L. H., \& Liu, T. (2017). Knowledge transfer in buyer-supplier relationships: The role of transactional and relational governance mechanisms. Journal of Business Research, 78, 285-293.

Luo, Y., Liu, Y., Yang, Q., Maksimov, V., \& Hou, J. (2015). Improving performance and reducing cost in buyersupplier relationships: The role of justice in curtailing opportunism. Journal of Business Research, 68(3), 607-615.

Martínez Sánchez, A., \& Pérez Pérez, M. (2005). Supply chain flexibility and firm performance: a conceptual model and empirical study in the automotive industry. International Journal of Operations \& Production Management, 25(7), 681-700.

McColl-Kennedy, J. R., Hogan, S. J., Witell, L., \& Snyder, H. (2017). Cocreative customer practices: Effects of health care customer value cocreation practices on well-being. Journal of Business Research, 70, 55-66.

Mohsenzadeh, M., \& Ahmadian, S. (2016). The mediating role of competitive strategies in the effect of firm competencies and export performance. Procedia Economics and Finance, 36, 456-466.

Monczka, R. M., Petersen, K. J., Handfield, R. B., \& Ragatz, G. L. (1998). Success factors in strategic supplier alliances: the buying company perspective. Decision sciences, 29(3), 553-577.

Mooi, E. A., \& Frambach, R. T. (2012). Encouraging innovation in business relationships-A research note. Journal of Business Research, 65(7), 1025-1030. 
Moorman, C., Zaltman, G., \& Deshpande, R. (1992). Relationships between providers and users of market research: the dynamics of trust within and between organizations. Journal of marketing research, 29(3), 314-328.

Morgan, R. M., \& Hunt, S. D. (1994). The commitment-trust theory of relationship marketing. Journal of marketing, 58(3), 20-38.

Mowday, R. T., Porter, L. W., \& Steers, R. M. (2013). Employee-organization linkages: The psychology of commitment, absenteeism, and turnover: Academic press.

Mukhopadhyay, T., \& Kekre, S. (2002). Strategic and operational benefits of electronic integration in B2B procurement processes. Management Science, 48(10), 1301-1313.

Nam, K., Kim, Y., Yim, M., \& Nam, L. (2009). A study on the relationships among supply chain risk components, commitment, trust, and business performance. Asia Pacific Journal of Information Systems, 19(4), 179-200.

Narver, J. C., \& Slater, S. F. (1990). The effect of a market orientation on business profitability. Journal of marketing, 54(4), 20-35.

Nuryakin, N., Aryanto, V. D. W., \& Setiawan, M. B. (2018). Mediating effect of value creation in the relationship between relational capabilities on business performance. Contaduría y administración, 63(1), 9.

Ordoobadi, S. M., \& Wang, S. (2011). A multiple perspectives approach to supplier selection. Industrial Management \& Data Systems, 111(4), 629-648.

Palma, F. C., Trimi, S., \& Hong, S.-G. (2018). Motivation triggers for customer participation in value co-creation. Service Business, 1-24.

Payne, A. F., Storbacka, K., \& Frow, P. (2008). Managing the co-creation of value. Journal of the academy of marketing science, 36(1), 83-96.

Qalati, S., Yuan, L., Iqbal, S., Hussain, R., \& Ali, S. (2019). Impact of Price on Customer Satisfaction; mediating role of Consumer Buying Behaviour in Telecom Sector. International Journal of Research, 6(4), 150165.

Ramaswamy, V., \& Gouillart, F. (2010). Building the co-creative enterprise. Harvard business review, 88(10), 100-109.

Ramaswamy, V., \& Ozcan, K. (2014). The co-creation paradigm: Stanford University Press.

Roy, S., \& Sivakumar, K. (2010). Innovation generation in upstream and downstream business relationships. Journal of business research, 63(12), 1356-1363.

Selnes, F., \& Sallis, J. (2003). Promoting relationship learning. Journal of marketing, 67(3), 80-95.

Swaminathan, J. M., \& Tayur, S. R. (2003). Models for supply chains in e-business. Management Science, 49(10), 1387-1406.

Teece, D. J. (2014). The foundations of enterprise performance: Dynamic and ordinary capabilities in an (economic) theory of firms. Academy of management perspectives, 28(4), 328-352.

Venkatraman, N., \& Ramanujam, V. (1986). Measurement of business performance in strategy research: A comparison of approaches. Academy of management review, 11(4), 801-814.

Verma, R., Rajagopal, \& Mercado, P. R. (2013). Impact of service co-creation on performance of firms: the mediating role of market oriented strategies. International Journal of Services and Operations Management, 15(4), 449-466.

von Hippel, E. (2017). Free Innovation by Consumers - How Producers Can Benefit: Consumers' free innovations represent a potentially valuable resource for industrial innovators. Research-Technology Management, 60(1), 39-42.

Wang, Q., \& Jap, S. (2017). Benevolent dictatorship and buyer-supplier exchange. Journal of Business Research, $78,204-216$.

Williamson, P. J., \& De Meyer, A. (2012). Ecosystem advantage: How to successfully harness the power of partners. California management review, 55(1), 24-46.

Wu, F., Li, H., Chu, L., \& Sculli, D. (2013). Supplier selection for outsourcing from the perspective of protecting crucial product knowledge. International Journal of Production Research, 51(5), 1508-1519.

Zaheer, A., McEvily, B., \& Perrone, V. (1998). Does trust matter? Exploring the effects of interorganizational and interpersonal trust on performance. Organization science, 9(2), 141-159.

Zhang, Q., Vonderembse, M. A., \& Lim, J.-S. (2003). Manufacturing flexibility: defining and analyzing relationships among competence, capability, and customer satisfaction. Journal of Operations Management, 21(2), 173-191. 